\title{
A Norm of Aesthetic Assertion and Its Semantic (In)Significance
}

\section{John Collins}

\section{School of Politics, Philosophy, Language, \& Communication,}

\author{
University of East Anglia
}

\section{John.collins@uea.ac.uk}

\begin{abstract}
The paper proposes that the distinctive features of aesthetic assertion are due to a special norm governing such assertion rather than any semantic features of aesthetic predication. The norm is elaborated as a (more or less faithful) reading of Kant's analysis of aesthetic judgment,. Apart from the proposed norm capturing various features of aesthetic assertion, it is supported by various linguistic considerations that point to the semantic profile of predicates of personal taste and aesthetic predicates being in fact alike with respect to the role of a judge or experiencer in the interpretation of the respective kinds of assertions. The difference between the two, therefore, must have a different source than the understood role of an agent, viz. the advertised norm. In particular, it is argued that the role of an explicit agent in both predicates acts to signal a presupposition of another agent having a different experience or judgment from the speaker rather than an articulation of the content of the predicate itself or a determination of its truth value.
\end{abstract}

Keywords: aesthetic assertion; Kant; norm of assertion; predicates of personal taste.

\section{1: Introduction}

The semantics of aesthetic predicates and their host judgments have only recently attracted sustained inquiry (exemplified by the Young (2017) collection and a special issue of Inquiry (2016)). This tardiness is somewhat odd for there is an obvious sympathy between the much- 
discussed predicates of personal taste (PPTs) (tasty, fun, exciting, etc.) and aesthetic predicates (beautiful, ugly, elegant, graceful, etc.). Roughly, opinion on the sympathy divides into two. On the one hand, some theorists hold that aesthetic predicates are best understood as a species of PPT. This kind of position need not deny that aesthetic judgment has distinctive features; it only seeks to show that the explanation of the semantics of aesthetic predicates does not require any novel or bespoke semantic, syntactic, or lexical machinery beyond what works for PPTs (cp., MacFarlane, 2005; Kölbel, 2008, 2016; Egan, 2010; Sundell, 2016, 2017). On the other hand, some theorists claim that aesthetic predicates are linguistically distinct in having features of both relative and absolute gradable adjectives (cp., Liao et al., 2016; Stojanovic and McNally, 2017). ${ }^{1}$ The present paper charts an independent course in arguing that aesthetic judgment is significantly distinct from that of personal taste in precisely not being personal, but expressive of a peculiar kind of experience-dependent universal claim, even though the linguistic profile of the respective predications is in fact alike. Central to this thought will be the idea that in both cases the explicit provision of a judge or experiencer signals a presupposition that the judgment of the speaker differs from some other agent, rather than an articulation of the content of the predicate in the PPT case but not the aesthetic one. What is distinctive about aesthetic judgment, therefore, falls outside of semantics proper and is to be explained by a special norm of assertion.

The paper's first half will suggest that aesthetic judgment is governed by a particular norm under which the judgment is experience-dependent but nonetheless treated as universal. This combination of features is norm-governed, according to my thesis, because it is not due to the

\footnotetext{
${ }^{1}$ These theorists view aesthetic predicates as expressing a comparison class of evaluation, like relative adjectives, while lacking a contextual standard, like absolute adjectives. The latter feature is reflected in the infelicity of an explicit judge phrase (e.g., for me); see $\S 4$.
} 
semantic or truth-conditional properties of the relevant predicates. The norm will be derived from two central features of Kant's analytic of aesthetic judgment in his Critique of the Power of Judgment (1790/2000). Appeal to Kant in the linguistic literature is not common; endorsement rarer still. ${ }^{2}$ In the paper's second half, once the norm is clearly in view, I shall argue that PPTs and aesthetic predicates are, indeed, alike, but not because they obligatorily express a role for an experiencer or judge in order to be truth-evaluable, but because of a lack of a peculiar experiencer-centric semantics many suppose for PPTs. In this light, as already intimated, the role of an explicit judge/experiencer in a for me phrase attached to the respective predicates will not be revelatory of the semantics of either, but mark a presupposition otherwise absent from the predicates. The differences there are between the relevant kinds of assertion, therefore, call for an extralinguistic explanation, which is precisely what the proposed norm provides.

\section{2: Aesthetic judgment: a first pass}

As a first pass, let an aesthetic judgment be defined as follows:

(AJ) A judgment $F a$ expressed by speaker $S$ is aesthetic iff, in predicating $F$ of $a, S$ expresses a positive/negative evaluation on the appearance of the object/event/scene $a$.

A clear problem with $(\mathrm{AJ})$, one might think, is that it offers little indication of what a specifically aesthetic predicate might be as opposed to just any old predicate used to express an evaluation of the appearance of something. Many descriptive predicates fulfil the role of $F$ without being aesthetic in any special way. A table may be said to be shabby, which describes the table as being in a certain state of disrepair (not brand new, an unfinished surface, etc.), but

\footnotetext{
${ }^{2}$ Kant remains key, of course, to many related topics concerning aesthetics, such as testimony; see Gorodeisky (2010), Hopkins (2000, 2011), Robson (2018).
} 
the judgment may be positive (think North London hipster bar with broken school furniture), negative (think top-end antiques market), or simply neutral. Likewise, many predicates have an aesthetic-independent life, but still regularly show up in aesthetic judgment (dynamic, balanced, powerful, striking, etc.) (see Sibley, 1959). Such concepts have a thick content and possess no essential thin evaluative core. Indeed, many seemingly paradigmatic aesthetic predicates can be used neutrally, as evident in context, or with a construal contrary to the conventional polarity, as indicated by a concomitant explicit evaluation. For example, one might say, without irony, The Holocaust movie was pretty, where it is understood that this is a failing (Godard described Schindler's List as 'max factor'). Similarly, one might say, Terence Malik's landscapes are beautiful, but essentially nature porn, unlike Tarkovsky's evocations of the elemental. More prosaically, all of the paradigmatic aesthetic predicates can be employed non-aesthetically in the sense of indicating a positive or negative experience without reference to the particular appearance of a thing or scene:

(1)a After midnight, the party turned a bit ugly

b It was such a beautiful wedding — all my old friends were there and everyone got on so well.

In short, there appears to be no thin evaluative aesthetic predicates as such, not even beautiful; that is, there is no especial aesthetic evaluative content that is part of the lexical content of a certain class of expressions. Instead, there are aesthetic judgments, which express certain aesthetic concepts that appear to be variously linguistically expressible rather than being dependent upon a particular predicate or construction. Still, in a range of its salient uses, beautiful and related predicates used as synonyms (sublime, elegant, exquisite, etc.) express positive aesthetic concepts. I shall argue that, as so construed, the predication of beauty has a distinctive assertoric signature in the sense that there is a norm governing how a speaker might 
properly be in a position to make aesthetic judgments as opposed to mere descriptive judgments that might or might not be associated with an evaluation (recall shabby). Such a norm reflects the content of the concepts expressed by the relevant predicates insofar as such a peculiar norm is operative in the way speakers may be rightly challenged when making aesthetic predications. In this sense, the norm does not generically cover all assertions.

Our concern, then, is for the distinctive features that associate with the expression of the concept of beauty as a notion of positive aesthetic evaluation. In the next section, I shall turn to beauty proper. My aim there is to explain how Kant's central insight into aesthetic judgment can be articulated and defended as an aspect of a norm concerning a speaker's entitlement to make the relevant judgment, and what demands a speaker must embrace in expressing such a judgment. The consequences of these claims for the syntax-semantics of aesthetic predicates will be taken-up afterwards.

\section{3: A norm of aesthetic assertion}

Before turning to the question of a norm of aesthetic assertion in particular, the notion of an assertoric norm in general needs to be explained. By a norm of assertion, I mean a condition a speaker must satisfy in order for them to be in a proper position to make the assertion at hand. If the condition is not satisfied, then the assertion ought not to be made, or be retracted. The speaker is liable for the condition obtaining. For example, Williamson's (2000) muchdiscussed norm of assertion has it that:

(NA) $S$ may assert that $P$ only if $S$ knows that $P$.

On the assumption that knowledge is factive, this means that if $P$ is false, then a speaker is wrong to assert $P$, no matter what evidence or conviction they might otherwise have. Of course, $S$ might be blameless, cognitively speaking, for evidence might well erroneously point towards $P$; still, $S$ is wrong to make the assertion, if $P$ is not the case. In general, if it can be shown that, 
$P$ is not the case, then $S$ should withdraw the assertion notwithstanding any weight of evidence or desire for the claim to be true. Note that on this proposal, and other such proposals, both weaker and stronger, the norm does not pertain to any particular predicate, concept expressed, or topic of discourse, but applies, rather, to the speech act of assertion, whatever the predicate. ${ }^{3}$ My contention, by way of Kant, is that there is a peculiar norm of aesthetic assertion. The need for such a specific norm arises because a speaker of an aesthetic assertion is not simply stating a putative fact towards which everyone should have fidelity; the speaker is also avowing her own responsiveness to an experience that is the fundamental basis for the judgment. A

speaker's fidelity is directed, therefore, not so much to the object out there, but to the character of her experience elicited by the object, a character everyone else's experiences should realise.

I do not, therefore, propose the putative aesthetic norm to be in opposition to an appropriate generic norm of assertion; that is, for present purposes, I am happy to recognise some such generic norm as NA holding over the aesthetic realm. A special aesthetic norm caters for the distinctive nature of aesthetic judgment where the very conditions for the assertion to count as aesthetic, qua evaluative, pertain to the experiential status of the speaker in making the very judgment. Thus, in the aesthetic realm, it is not so much that one intends one's assertions merely to track the truth — of course one does intend that—but one also avows having had a particular kind of experience. Yet one's having had the experience is not constitutive of the truth of what is said, for one is not merely making a claim about oneself (the content is not individualistic). If one were, one's judgment on the matter would have a privileged status that would resist ready challenge or disagreement or revision, but none of that is the case for

\footnotetext{
${ }^{3}$ See Brown and Cappelen (2011) for varied positions on the nature of assertion and its associated norm.
} 
aesthetic talk (see $\$ 4,5)$. Still, without one's experiences being the basis for one's judgment, the assertion misfires, much as an actor or a liar prescinds from a general norm of assertion.

One might be initially sceptical that there is or should be any distinctive norm hereabouts. My ambition is to show that there is such a norm precisely because what is particular to aesthetic talk cannot be understood if we take aesthetic assertion to be mere truth tracking, and which, furthermore, can't be explained semantically as features of the meaning of the relevant aesthetic predicates. The operation of the norm thus becomes compelling as a means of explaining what is distinctive to the aesthetic realm of judgment. We shall see precisely how this consideration plays out with some detailed examples.

The basic normative claim I endorse is as follows:

(NAA) $S$ may assert that $x$ is beautiful only if $S$ takes a pleasure in the experience of $x$ that is not based upon idiosyncratic features or aetiology of the experience, and so the judgment is to be commended universally as based upon $S$ 's experience of $x$ independent of all other factors peculiar to $S$.

As mentioned, I don't intend this norm to supersede a more generic norm, but rather to unpack what is involved in sincerely applying aesthetic concepts in assertions. So, suppose that NA is a general norm of assertion. NAA does not suggest that truth is not also a norm for aesthetic assertion, but says that conditions in addition to truth are necessary for aesthetic assertion to be felicitous. Suppose Smith asserts that Ozu's Tokyo Story is beautiful (/exquisite/sublime/etc.). Smith, however, has not seen the film; he gets his opinions from critics' polls, which consistently rate Tokyo Story very high. According to NAA, Smith is not in a position to make his assertion. Tokyo Story is filmmaking of the highest order, so what Smith said is true, but that does not suffice to allow Smith to assert it, for the aesthetic judgment must be experiential. Smith must, in part, be indicating something about his own experience as the basis for the 
judgment, even though the truth of the assertion cannot rest upon any idiosyncratic features of Smith, such as recollection of his own elderly parents. That is what NAA claims. A judgment of beauty is peculiar in that it avows an experience that the speaker reckons to be a basis for universal accord. At any rate, that is what I intend to argue.

According to NAA, therefore, a speaker will be wrong to make an aesthetic assertion if various conditions are not met beyond truth, which NAA distils in terms of an experiential universal condition, i.e., the speaker has had relevant experiences, and the pleasure they elicit that informs the judgment cannot be sourced to anything merely idiosyncratic in the speaker. This might initially strike one as too onerous a burden for speakers, but I hope to show that it fits the shape of our aesthetic judgments. What is certainly true, as Kant well recognised and as I shall discuss in $\S 4$, is that many judgments concerning aesthetic matters are in fact ones concerning agreeableness or mere personal taste (think Smith and his recollections). We should also recognise that many people are happy to bullshit, in Frankfurt's (1986) sense, in matters aesthetic, either feigning pleasure or interest, or simply talking about things of which they have no experience. There is an interesting issue hereabouts concerning testimony in aesthetics, which I shall broach in $\S 4$. Suffice it to note now that NAA is not intended to capture descriptively our aesthetic talk, but to constitute a norm on whose terms speakers may be challenged, and according to which they should reflect on and revise their judgments. The import of the norm is that if speakers are not open to such norm-governed challenge and revision, then they are not speaking aesthetically, but are, instead, confused, playacting or bullshitting.

It bears emphasis now that I do not intend NAA to be precisely what Kant had in mind; I intend NAA to be stand-alone correct regardless of any fidelity to Kant. Indeed, Kant avers that the 'claim to universal validity so essentially belongs to any [aesthetic] judgement... that without thinking this it would never occur to anyone to use this expression [i.e., beauty]' 
(5:214). Kant here appears to be reckoning 'universal validity' to be a semantic feature of aesthetic predication, rather than a norm that one may break and still be making sense or, indeed, be speaking truthfully. Contemporary distinctions between semantic properties and norms, however, do not map easily onto Kant's claims. I do intend NAA to be essential to aesthetic assertion in the sense that failure to cleave to it renders the talk defective, not merely lacking in justification. After all, many kinds of claims can and are made without justification in the absence of a special norm; rather, eschewing NAA undermines the very kind of claim being purported to be put forward. It is consistent with such failure that what is said is nonetheless true, much as a liar or actor may accidentally speak the truth.

Kant analyses aesthetic judgment in terms of four 'moments', two of which inform NAA.

\section{4: Universality}

In Kant's (5: 206-7) first 'moment', he deems the merely agreeable to be distinct from the aesthetic with respect to disinterestedness. In essence, the agreeable corresponds to what is expressed by a PTT such as tasty or fun (5: 212). If one only considers disinterest alone, one might think that, for Kant, aesthetic judgment expresses a peculiar kind of PPT notion, one that is experiential and expressive of pleasure, much like tasty or fun, but detached from any desires or their satisfaction. On such a view, it is at least coherent for one to judge, say, that $x$ is fun, but have no desire for $x$. On such a construal, aesthetic judgment would remain idiosyncratic or individualistic; for example, one's finding $x$ to be tasty would have no bearing on how others do or should find $x$ to be. Kant's second 'moment' that appeals to universality crucially distinguishes aesthetic appreciation from any mere idiosyncratic response to an experience.

The standard understanding of PPTs is that they count as personal because PPT judgments can vary between individuals without contradiction or incoherence. What an individual finds fun or tasty, say, is a matter for them, and any agreement between individuals might as well be 
a coincidence for all the bearing it has upon the content judged, i.e., the basis for the agreement might be to do with basic facts of human digestion, say, that is not the topic of PPTs. As Kant (5: 212) puts it: 'with regard to the agreeable, the principle Everyone has his own taste (of the senses) is valid'. Since Kant wrote, this relativity feature of taste is often expressed as the thought that judgments of tastiness (etc.) give rise to faultless disagreement, where individuals appear to disagree with each other, with no-one being at fault. ${ }^{4}$ Pro tem, the relevant feature of PPTs is that their truth is fixed relative to a given individual (or group), and so count as personal or idiosyncratic. Linguistically, this feature is often said to be captured by PPTs happily accepting adjunct judge phrases (prepositional phrases) that index the predicate to a particular individual or group:

(2)a The cake is tasty for me/us/them

b ?The cake is frozen for me/us/them

(2a) is supposedly fine. The status of (2b) appears to be more dubious. One could coherently utter $(2 b)$ in a peculiar context where impressions of the frozen status of a cake are what observers might differ on. Note that in such a case it is not the physical state of the cake that is at issue (its temperature, say), but how different speakers judge the cake to be relative to their standards of frozenness. Still, (2b) is anomalous on the off-the-bat reading where we don't take

\footnotetext{
${ }^{4}$ The notion of faultless disagreement in the modern era originates with Hume and Kant, but in contemporary literature is mostly sourced to Wright (1992) and Kölbel (2004). For present purposes, I remain neutral on how best to analyse faultless disagreement and on whether it militates for or against any particular position on the determination of content. My two claims of substance regarding the notion, however, are that it does not apply to aesthetic judgment and has no linguistic signature.
} 
a cake's physical states to be a function of, or variable over, a person's interest in it, such as one about to eat it.

The basic agent-relativity of PPT's is standardly approached in two different ways. A classic contextualist conception of PPTs is that such an indexing of the predicate to a judge is covertly realised, when not overt, such that, as a matter of the proposition expressed, a PPT entails an agent or judge (in a given context of utterance). Thus, the bare The cake is tasty (as uttered in some context) expresses a proposition concerning some definite individual—principally, the speaker, in the absence of countervailing information (e.g., Glanzberg, 2007; Schaffer, 2011). ${ }^{5}$ In distinction, a so-called relativist position takes a context-relevant judge to fix a truth-value via a standard of assessment of an already fully saturated proposition (Kölbel, 2004; Richard, 2008; Lasersohn, 2005, 2017; MacFarlane, 2007, 2014). This contextualist vs. relativism debate is mostly conditioned by the desideratum to understand and explain disagreement phenomena. Both sides agree that the truth of a PPT judgment $F a$ depends upon at least one particular individual judging $a$ to be $F$. Why should this be? Plainly, it is because a PPT expresses some feature of what it is like to have the relevant experience of the referent of the subject of the PPT. In this regard, any agreement between speakers is adventitious as regards the content expressed.

As I shall presently argue, the status of the judge adjunct in PPT constructions is somewhat more complex than either of the two approaches acknowledges, for the adjunct carries a contrastive presupposition rather than being expressive of the content of the PPT (as the contextualist would have it) or determinate of a truth value (as the relativist would have it). That is, the adjunct does not merely express who finds something fun or tasty, but also

\footnotetext{
${ }^{5}$ Also see Plunkett and Sundell (2013), López da Sa (2015), and Silk (2016) for versions of contextualism that go via discourse factors.
} 
communicates that this person is distinguished from others, whose judgment might differ or be unknown. If there are no such relevant others, then the presence of the for/to $x$ adjunct is anomalous. Still, for Kant at least, judgments of beauty are unlike PPTs due to the latter accepting the relevant adjuncts, whereas the former do not. I think Kant's basic point can be captured even if we relinquish, as we shall, the idea that aesthetic predicates and PPTs fundamentally differ as regards their acceptance of judge adjunct phrases. Let's now see this.

The second 'moment' tells us that aesthetic judgment is universal and so not personcentric. At its barest, this claim amounts to the thought that aesthetic predicates are not indexed to individuals. This presents an apparent paradox, for aesthetic judgments are experiential, and it is my experience that essentially informs $m y$ judgment, not anyone else's, it seems. I'll get to the paradox shortly. Before doing so, let's briefly reflect on why judgments of beauty are not simply personal opinions of taste, and so why they are unlike PPT judgments.

Consider the examples in (3):

(3)a ?The film is beautiful for me

b ?The film is beautiful, but there is no reason anyone else should think so

An off-the-bat discourse-initial utterance of (3a) is decidedly odd, for since no other judge or experiencer is salient, there is no-one the speaker is in contrast with regarding their attitude to the film. At best, it is as if the speaker is hedging their assertion in expectation of disagreement. If we took the self-referential for me to be part of the content of the predicate, then it would be difficult to see why the explicit form is odd when discourse-initial, rather than just needlessly explicit (compare: I ate/I ate some food). The explanation NAA offers is that an aesthetic assertion is precisely not personal, so (3a) misfires without a contrast being in play between the speaker and some other agents. In fact, Liao et al. (2016, p. 623-4) report that corpora fail to exhibit constructions such as (3a). McNally and Stojanovic (2017, p. 31) suggest that such 
judge/experiencer modifications are illicit due to the aesthetic adjective not selecting an experiencer argument. Yet for $x$ is not a grammatical argument of any adjective, so McNally and Stojanovic's claim is not so much an observation about the peculiarity of aesthetic predicates as a hypothesis concerning the semantics of the predicate that stands in need of support. Further, (3a) is perfectly acceptable when not discourse-initial, as, say, a response to someone disparaging the film at issue. Here, by uttering (3a), one would be signalling a disagreement, or perhaps simply be declining to engage further on the matter.

So, (3a) appears to be unavailable to spell out or to clarify, even, what one meant, say, by initially claiming that the film is beautiful, but is OK when used contrastively. In short, the adjunct phrase carries the contrastive presupposition that someone else doesn't find the film beautiful or is doubtful of it. The adjunct phrase does not unpack the content of the assertion of the bare aesthetic property. Similarly, however, and here I depart from Kant, an off-the-bat (discourse-initial) utterance of The ice cream is tasty for me is also odd, for, just as with aesthetic assertion, it carries the contrastive presupposition of some other agent not liking the ice cream. The oddity here, however, arises from the expected assertion of an utterance of The ice cream is tasty precisely to be speaker-centric; we do not, in particular, take the speaker to be judging for others, so the speaker's self-reference appears redundant in the absence of another salient judge rather than at odds with the expected content. Since NAA does not apply to PPTs, we predict such a difference. I hope this claim about the presuppositional nature of judge adjuncts is intuitively plausible; I return to the proper understanding of the judge adjunct phrase in $§ 6$ once some semantic background is in place. ${ }^{6}$

\footnotetext{
${ }^{6}$ It bears emphasis that the adjunct phrase is happy when in the scope of an adverbial:
}

(i)a You are too/so beautiful to me 
(3b) points in the same direction. If the first clause expressed a mere personal judgment, then there would be nothing odd about the second clause. As it is, the second clause appears to undercut the first clause. If the film is beautiful, then, in the absence of any of other considerations, everyone else should think it beautiful, too. In this sense, a speaker of the first clause is not saying something merely about how things are for herself.

This is exactly what we should expect, if NAA governs aesthetic assertion. Since such assertion is not mere self-reportage, but also carries a universal/evaluative aspect, a speaker cannot index the predication of beauty just to their own experiences, as (3a) does, or decline to generalise from their own experience, as (3b) does. So far, then, NAA is corroborated by the reasoning Kant offers, notwithstanding the presuppositional character of judge adjuncts in both cases of personal taste and aesthetics.

As alluded to above, however, the universality of aesthetic judgment presents a seeming paradox. On the one hand, notwithstanding the status of (3a), a judgment of beauty must be experiential, much like a PPT. ${ }^{7}$ Consider:

(4)a ?Dreyer's Day of Wrath is beautiful-I've never seen it, so am looking forward to the

b You are beautiful to me

(ia) is a compliment expressing the overwhelming appearance of one's love (hence its use in songs), whereas (ib) is really not the thing to say to curry favour. It implies, contrastively, that others might not find the addressee beautiful. This contrast supports the reasoning offered in the main text.

7 As regards PPTs, this condition is sometimes termed 'the direct experience requirement/inference' (cp., Stephenson, 2007; Pearson, 2013). I am extending the requirement to aesthetic judgment (cp., Ninan, 2014). 
screening.

$\mathrm{b}$ ?L'Eclisse is the most gorgeous black and white film-a lot of the critics say

so; I must watch it.

c ?I have never really seen Bresson, but Schrader has convinced me that his work is sublime.

$\mathrm{d}$ ?The ice cream is tasty, but I don't like it/have never tried it ${ }^{8}$

These examples bear upon the plausibility of aesthetic testimony; for now, I shall just spell out their apparent fit with NAA, and return to testimony shortly. Judgments that $x$ is beautiful/gorgeous/sublime made by someone who denies having experienced $x$ badly misfire. It is not that the judgments are rendered false-Dreyer, Antonioni, and Bresson are that good. The problem from the perspective of NAA is that the speaker is denying a crucial basis for her having that kind of thought in the first place. One cannot judge an object beautiful without experiencing it; mere hearsay or testimony, even if an argument is mounted, appear not to suffice. The thoughts of critics are fine in their place, but they cannot substitute for experience. Kant (5: 340) expresses this thought by saying that there can be 'no proof' of an aesthetic judgment, by which he means that there can be no mere conceptual determination that an object

\footnotetext{
${ }^{8}$ A speaker-centric construal is not mandatory. For instance, parents often 'exocentrically' adopt the perspective of their children when it comes to certain experiences, regardless of what the parent actually judges (at any rate, what the parent wants or expects the child to experience is what is important): 'Try it! It's really tasty!', 'Have a go! It's great fun', etc. Outside of such projection, the PPT requires modification, if it is not to be read as a first-person assertion, an avowal.
} 
falls under the concept of beauty. In this sense, beauty has no definition, whose conditions can be checked off for any given object under consideration, regardless of whether experienced or not. For one to judge $x$ to be beautiful, one must have an experience of $x$, upon which the judgment is in some sense reporting, i.e., one is universalising one's experience-dependent judgment. ${ }^{9}$ The PPT judgment is distinct insofar as where an experience is required, there is no sense in which a speaker is under any obligation or even inclination to universalise.

Some writers consider aesthetic judgments, unlike personal taste judgments, not to be experience-dependent. Silk (2016, p. 211), for instance, suggests that an utterance of 'The Botticellis are beautiful. I haven't seen them myself...' is OK (cp., Kölbel, 2016, who takes it to be a desideratum for a theory of aesthetic judgment to explain deference to the aesthetic expert). Again, nothing has gone wrong grammatically here, but the assertion misfires in the sense that the speaker is denying the sole basis upon which she would be in a position to make the judgment. In that sense, the mistake goes against the NAA rather than any semantic or grammatical conditions.

\footnotetext{
${ }^{9}$ Kant (5: 229) draws the distinction between 'free' and 'dependent' or 'adherent' beauty, where the latter kind of judgment is dependent upon a concept of what the thing experienced is or is supposed to be; hence, a notion of perfection is concomitant with dependent beauty. In the text and throughout this paper, I have 'free' beauty in mind, which is what Kant's four 'moments' seek to characterise.
} 
The difference of opinion about such cases can be diagnosed, I think, by noting how easily an adverbial hedge or some other modification rescues the cases in (4) and Silk's own example—at any rate, everyone should acknowledge the improvement ${ }^{10}$ :

(5)a Dreyer's Day of Wrath is apparently beautiful...

b The Botticellis are said to be beautiful

The crucial point is that the unmodified cases, such as those in (4), cannot be construed as expressing the modified content expressed in (5), although it is only such content a speaker would be entitled to assert without experience of the relevant film or painting; that is, only the modification saves the speaker from rightful challenge:

(6) A: The Botticellis are beautiful

B: Oh, you've seen them?

A: No - I read a review.

B: OK, you mean we should see them-they got a good write up?

A: Yeah, apparently they are sublime. I trust his judgment.

The point here is that A's initial unmodified statement can be and is naturally challenged, regardless of the ultimate status of the paintings; that is, here, $\mathrm{B}$ is not so much disagreeing with A on the ultimate quality of the Botticellis, as suggesting that A is just not in a position to make the judgment he purports to offer. The dialogue would make no sense whatsoever if A's initial statement were appropriately modified with the relevant adverbial (The Botticellis are apparently/said to be beautiful), and so NAA appears to apply to the unmodified assertion in a

\footnotetext{
${ }^{10}$ See Pearson (2014) and Ninan (2014) for insightful discussion of hedging with regard to PPTs.
} 
way it does not to the modified one. This is predicted by NAA itself, for the modified assertions are precisely implying or presupposing a lack of the experience necessary for the bare aesthetic judgment to be OK. There is, to be sure, nothing linguistically anomalous about using bare aesthetic notions to express expectations or likely opinions on films or paintings, but one is being misleading at best, if the hear-say nature of one's assertion is not made explicit. An explanation is provided by NAA: one is not in a position to make the aesthetic judgment without the relevant experience; no substitute will do, not even a trusted critic.

Analogous normative sanctions are not apposite with other realms of discourse. One may freely assert mathematical theorems, say, without having a clue how to prove them; mutatis mutandis for empirical claims. Such a difference tells us how aesthetic assertion is special, not that such peculiar assertion is illusory or just a form of PPT assertion. In aesthetic judgment, the experience is not evidential, with divergent non-experiential evidence serving equally well, where available. The experience is constitutive of the judgment being aesthetic; without it, an agent would effectively be dissembling, much as a liar is, who might accidently speak truthfully.

What I have argued so far might seem to be dismissive of the complexity of the 'aesthetic testimony' debate. ${ }^{11}$ My immediate concern, however, is not for testimony. I don't doubt that testimony can be a source of knowledge across many domains, perhaps every domain. In particular, then, a competent judge of aesthetic matters can freely appeal to testimony in support of a judgment. Thus, it is common for an aesthetic judgment to be challenged or supported via appeal, say, to the weight of critical consensus. Insofar, then, as the testimony debate concerns aesthetic knowledge, I am happy to acknowledge that aesthetic knowledge is

\footnotetext{
${ }^{11}$ See, for example, Robson (2012, 2015, forthcoming), Meskin (2004), Gorodeisky (2010), and Hopkins (2000, 2011).
} 
acquirable via testimony. All I mean to exclude is testimony being the basis of aesthetic judgment in the absence of experience; that is, we should be pessimistic of aesthetic testimony only if it is presented as a substitute for experience as a source of aesthetic judgment. In Hopkins's (2011) terms, I am here rejecting the availability role of aesthetic testimony, but not its usability. That is to say, testimony alone does not make available aesthetic judgments, but testimony may still be used in support of such judgments. The Kantian reason for this is that while experience is constitutive of aesthetic judgment, the judgment is not self-confirming, for it can be doubted (see $\S 5)$.

To see the point here, consider Robson's (2018) appeal to the familiar Humean 'test of time' criterion, whereby a historical consensus about an aesthetic matter is a supposedly genuinely reliable testimonial source of knowledge that is superior to the view of a single critic or one's own fallible taste. There is something correct to this thought insofar as a robust consensus on some aesthetic matter is presumably not an accident or a mere reflection of widespread prejudice. It doesn't follow, however, that an agent would be treated as being in a position to make the relevant aesthetic assertions without experience, as evidenced by the kind of cases just discussed. Robson (ibid, p. 39) writes:

Levinson goes so far as to classify the judgement that 'the Adagio of Beethoven's Third Symphony' possesses certain aesthetic properties 'on the basis of centuries of testimony' as a paradigmatic example of a legitimate second-hand judgement.

Let's suppose this is correct. It does not put a speaker in a position to say that the Beethoven adagio is beautiful or sublime, if they have never heard it. The judgment is not made available via the testimony. The import of the Humean criterion, which I don't deny, is that it signals a deep concord between those who have had the relevant experiences, such as those familiar with Beethoven; it does not offer a substitute for experience, as if genuine aesthetic judgment could 
typically be exercised vicariously. Consequently, one could agree with a speaker-think they said something true in agreement with the consensus-while challenging their right to say it.

One motivation, expressed by Robson and others, to question pessimism about aesthetic testimony is that it can seem that the only alternative to the rights of testimony is a blind trust in one's personal taste, which would appear to be legitimate only if aesthetic judgment were PPT-like. It is crucial for Kant, however, that aesthetic judgment is not a registering of the mere agreeable. Hence it is that there is a seeming paradox, where Kant insists upon an essential role for experience while equally insisting that aesthetic judgment has a universal cast under which one is not merely reporting on one's own experience. The paradox, therefore, is that aesthetic judgment appears to indicate a kind of experience that has a universal import on what one might judge without the experience being conceptually determinate. Moreover, the notion appears dubious anyway, for people disagree in aesthetic matters without there typically being attributable fault. Kant, however, does not suppose or even expect agreement. In Kant's (5: 213) terms:

$[\mathrm{H}] \mathrm{e}$ says that the thing is beautiful, and does not count on the agreement of others with his judgment of satisfaction because he has frequently found them to be agreeable with his own, but rather demands it from them.

Those who disagree are 'rebuked', and the idea that everyone has their own aesthetic taste is tantamount to there being 'no taste at all'. Thus, the very idea of faultless disagreement in the aesthetic realm amounts to the absence of judgment.

The demand for agreement may be questioned, of course, and certainly will be by the more pusillanimous. Allowing others to disagree with one, however, might merely indicate politeness or suggest a wish to avoid confrontation when matters are at issue that are not readily resolvable. If so, any lack of the relevant demand will be more readily sourced to generic norms 
of discourse than to any principles specific to aesthetics. To see the point here, consider Sundell's (2017, pp. 88-9) reasoning, who takes the Kant-like demand for agreement to be questionable.

Sundell (ibid., p. 88) offers the following dialogue:

(7) A: Titanic is a terrible movie.

B: I can see why you feel that way, but to me it's beautiful.

A: Fair enough.

Sundell (op cit.) describes such a dialogue as 'disappointing... [but not] bizarre. There is nothing confused, or incompetent, or semantically infelicitous about [it]' (idid., p. 89).

According to Sundell, an analogous dialogue pertaining to 'objective matters' offers the pertinent contrast:

(8) A: There are three people in my office.

B: I can see why you feel that way, but there are only two.

\section{A: Fair enough.}

Sundell does not take the putative contrast between these dialogues as being compelling evidence against a universalist understanding of aesthetic verdicts. His point, rather, is that the 'defusing' move of treating judgments as merely personal is only available in the aesthetic realm, and any 'normative demand' in aesthetics is non-obligatory. ${ }^{12}$

\footnotetext{
12 Sundell's $(2016,2017)$ own positive account takes as central the idea that interlocutors metalinguistically negotiate the range of evaluative and non-evaluative predicates alike as a matter of seeking agreement relative to a context as to how the relevant predicates ought to be
} 
Sundell's judgments may be disputed. A's 'Fair enough' response may be read as declining an argument without sanctioning what B says, much like the common use of 'Whatever', meaning, 'I'm not going to disagree with you, but I hardly affirm your view'. On such a construal, A's responses in both dialogues are perfectly OK. Sundell evidently means for A's responses to be read in some personal rather than indifferent manner, such that the first dialogue is fine, whereas the second is confused in some sense. There is, however, a clear epistemic difference between the dialogues that makes sense of the 'defusing' move in the aesthetic dialogue but does not reflect fundamentally different 'normative demands' between aesthetics and 'objective' discourse. It is straightforward to settle disputes concerning what number of things are in a room (presuming some agreed upon criterion of individuation), whereas it is not possible to resolve aesthetic disputes in a similar way. Hence, the second dialogue is bizarre, if read in the personal manner Sundell must intend, because the apparent dispute is easily settled, at least in principle, so why would A be concessive to the point of idiocy? Or, unless B has more to go on other than a seeming, what on Earth is he talking about? Why don't both parties just look into the room? In contrast, the first aesthetic dispute can't be settled in any easily agreed upon manner, so B's doubt about Titanic and A's concession to it might not be common, or even called for in the absence of other factors, but it is not epistemically bizarre. Crucially, this kind of epistemic difference does not mark aesthetic matters as being anything other than universal, as Kant precisely stressed, i.e., in the aesthetic realm, one judges for all without imagining any means of persuading all. I shall develop this idea in the following section.

used. For present purposes, I don't doubt that such negotiation is common; I simply suggest that such negotiation never usurps the normative role of experience in informing aesthetic judgment. 
The question remains why aesthetic judgment should be treated as a universal matter, if its basis is experiential. Kant offers a resolution to this quandary in the shape of a distinctive character to the experience of beauty that is not idiosyncratic to individuals. The 'free play' of the oscillation or search for concepts from the understanding appropriate to one's experience gives rise to a kind of pleasure in an awareness of one's one cognitive organisation, which is perfectly general (5.218-9). ${ }^{13}$ Thus, the pleasure that is constitutive of an aesthetic experience is a self-awareness of one's cognitive processes to which one is blind outside of such reflective moments. Plausible or not, this story is not part of aesthetic talk, although it might be a feature of aesthetic phenomenology. Regardless, all I take myself to have argued for is that aesthetic judgment is not merely personal, even though it depends upon the speaker's experience. In NAA terms, an aesthetic assertion must be grounded in experience, but is not treated as a matter of mere opinion that is free to vary from one individual to another.

\section{5: Necessity as normative}

Kant's fourth 'moment' claims that a certain necessity holds of judgments of beauty. The thought here is not that beauty is a necessary property of some objects but not others; nor even that we take the judgment at hand to be a necessary truth akin to a mathematic judgment. The claim, rather, is, as we should say nowadays, that aesthetic judgments are normative, i.e., we take them to be binding over all others who employ the same concepts; we demand the assent of others, or take ourselves to be speaking for all, when we make an aesthetic judgment. We have, as Kant (5: 216) puts it, 'a universal voice'. This aspect makes sense of predications of beauty not allowing a personal adjunct (for/to me) as a further elaboration of the predicate (see above and §6.2). Of course, the adjuncts are grammatically permissible, but they remove the

\footnotetext{
13 The principal point is effectively wrapped up in the Dialectic and via the evocation of the supersensible.
} 
sense of necessity or normativity constitutive of the concepts the predicates express. Beauty is thus aligned with truth and goodness in possessing a universally binding cast, rather than being merely personal. All of the cases in (9) are odd for the same reason:

(9)a ?That is true for me

b ?That is beautiful to me

c ?That is good for me [in a moral sense]

People, of course, do (unfortunately) speak in such ways, but in so doing they are not employing the respective notions with any normative force; on the contrary, the normative dimension is precisely being denied. There is a further connection between the concepts, too.

Kant seeks to explain the basis of the normative aspect of aesthetic judgment instead of being content to register it. The basic thought is that in making a judgment of beauty, the agent is not basing the judgment upon anything idiosyncratic or merely personal. The aesthetic pleasure is sourced, instead, to the 'free play' activity of their own mind, which in being a formal or architectural condition is universal, or taken to be so. Thus it is that the agent can speak for all when she speaks upon the basis of her own experience.

As above, we may demur on the precise phenomenological dynamic Kant details while adhering to the kind of grounding of the normativity of aesthetic judgment Kant articulates. One clear line of support comes from the sympathy between aesthetic and moral judgment. In the moral case, if a judgment is discovered to be based upon some self-interest or idiosyncratic or prejudicial consideration, then the claim is undermined qua a moral one. This is not to say that the judgment turns out to be incorrect in the sense of being false, but only that the speaker's standing as making a moral judgment is undermined. One can, and, indeed, should, secondguess or question oneself in this regard; just so for aesthetic judgments, Kant claims. A judgment of beauty will be undermined as such a judgment, if one recognises that one is 
judging on the basis of nostalgia, say, or some sentiment peculiar to oneself. As Kant (5: 216) has it:

Whether someone who believes himself to be making a judgment of taste is in fact judging in accordance with this idea can be uncertain... that it is supposed to be a judgment of taste, he announces through the expression of beauty. Of that he can be certain for himself through the mere consciousness of separation of everything that belongs to the agreeable and the good from the satisfaction that remains to him; and this is all for which he promises himself the assent of everyone: a claim which he would also be justified in making under these conditions, if only he were not often to offend against them and thereby make an erroneous judgment of tatse.

The point I wish to extract from Kant here is not that someone might be uncertain of the truth of their aesthetic judgment, or that they might be uncertain that they have even made a judgment. The uncertainty Kant appears to have in mind, rather, pertains to a judge not being able to be sure that their judgment is pure either because it is not free from idiosyncratic features of interest or emotion, which would render the judgment to be not genuinely universal, or because it is in fact a conceptual judgment concerning an object's function. In essence, if one cannot speak for others on the basis of one's experience, then one cannot speak for oneself as having a judgment that is not peculiar to one's own interests or history: 'only under the presupposition of a common sense (... the effect of the free play of our cognitive powers)... can the judgment of taste be made' (5: 238). Thus, an idiosyncratic or merely personal reason for a judgment of beauty belies the judgment, for the necessity of common assent is belied. There is, of course, no inconsistency in a piece of music, say, being both beautiful and inducing lovely memories in a listener. The point is that if the judgment of beauty is based upon such memories being elicited, then it is hardly a judgment the listener can demand of all humanity; after all, everyone has their own memories, and our judgments are hardly obligated to the 
memories of others, or even our own, for that matter. The upshot of this is that our capacity for aesthetic judgment might issue in erroneous verdicts. This need not be due to any sceptical concern, as if what seems beautiful might be revealed to be ugly after due deliberation. There might be such cases, but there is no reason to be so sceptical in general; at any rate, Kant entertains no such scepticism. Rather, an aesthetic judgment might be erroneous because the conditions for our making the judgment in the first place are not necessarily open to view, and so the judge might be quite deluded or just ignorant of the basis for their judgment, much as selfishness or neediness might present themselves as feelings of love. As in other cognitive realms, our biases and prejudices shape what judgments we make, and it is never too easy to recognise what such interfering factors are or when they arise.

So, aesthetic judgments demand agreement, and our open to doubt. As noted above with reference to Sundell's objection, it does not follow that there will be any agreement in fact. This feature tallies with how aesthetic predicates may be employed:

(10)a Everyone is wrong about Malik-what passes for beauty is mere nature porn.

b People just don't see the beauty in Ozu—their taste is tarnished by cinematic spectacle.

It is perfectly coherent for no-one to agree with one's judgment; indeed, given that it is appropriate to question the basis of one's own judgment, a fortiori, it is OK to question the judgments of others, even nigh-on everyone else (witness Tolstoy on Shakespeare). Of course, there is great agreement between people in aesthetic judgment, and it is hardly a virtue forone to be constantly contrary, still less obtuse. Kant's claim is merely that agreement is demanded by seriously upholding a judgment, not that agreement is to be found or even expected.

One might think that the kind of uncertainty Kant believes to be inherent to aesthetic judgment makes for a poor basis for a norm of assertion; after all, how might one cleave to a norm about whose application one is forever uncertain? In fact, however, it should be in the 
nature of a plausible norm that one can go freely wrong with respect to it, be mistaken; otherwise, the norm becomes expressive of a more physical or dispositional condition. Thus, the norm does not so much as guide or cause exercises of judgment, as if we establish a disinterested state of mind before judgment; instead, it makes sense of the counterfactual profile of judgment. For example, we would amend our judgment, if we were to find that it is informed by corrupting idiosyncrasies. This holds for the moral and aesthetic cases equally. If one were to realise that one's 'good actions' are actually self-serving, one might not desist from the actions, but one should certainly desist from thinking oneself moral because of such actions. Likewise, if one were to realise that one's fondness for Japanese 50s cinema was really an affectation born of intellectual insecurity, one should hardly continue to forward claims about the beauty of Ozu or Mizoguschi, at least not if one is remotely serious. Crucially, aesthetic judgment (and moral judgment too) involves reflection; it is not mandatory. A norm serves as a principle about how one ought to reflect to arrive at a stable judgment to be asserted. So, as Kant claims in the passage quoted above, one may consciously sieve one's taste so as to remove personal subjective factors, about which one has no interest in demanding, let alone expecting, concord with others. In this light, it might well be that most people most of the time rest content with judgments of agreeableness, but that itself will show up in people's lack of preparedness to demand agreement from others and to dispute about aesthetic matters.

My argument so far is that two of Kant's four 'moments' of the analytic of aesthetic judgment can be finagled into claims concerning the appropriateness and inappropriateness of certain kinds of assertion. In the remainder, I shall argue that the features of aesthetic assertion adumbrated are not semantically explicable as part of the linguistic content of aesthetic predication. Thus, NAA gains support as an extra-linguistic condition on aesthetic evaluation. This will be achieved by showing that aesthetic predicates have much the same semantic profile as PPTs, with both lacking a linguistic property indicating the role of a judge or experiencer. 


\section{6: The semantic profile of personal taste and aesthetics}

As argued in $\S 3$, a general norm of assertion is not triggered by the content of any particular word used, but by the kind of speech act. Our putative norm NAA is somewhat different, for it offers a special instance of a general assertoric norm that turns on the presence of a particular kind of predicate-paradigmatically, beautiful. In this section, I shall propose that the NAA becomes quite compelling, for the semantic profile of aesthetic predicates is relevantly the same as PPTs, but, as we have seen, they are distinct in terms of the demands they place upon their role in assertions. Hence it is that NAA, as an extra-semantic/syntactic factor, is supported as an explanation of this difference.

\section{1: Predicates of personal taste and their structure}

Let's agree that for a PPT construction to be true (as uttered in some context) there must be at least some experiencer or judge who experiences/judges $x$ to be fun/tasty/etc. Normally, the speaker would be understood to be the relevant agent, but it could be another person or simply an indefinite/arbitrary agent. An open issue is how the role for such an understood agent is realised. It might be semantically encoded, either in the syntax of the sentence (in the guise of a variable over experiencers, say) or as a feature of the meaning of the predicate or else be a feature of wider thought, such as our conception of what is involved in a thing being fun/tasty/etc. There are many considerations pertinent to this question (see Collins, 2013). In the space available, let me briefly show that there is good reason to be sceptical of some standard considerations for the claim that an experiencer/judge is semantically encoded in a PPT. This line of reasoning will buttress the essential role of the NAA, qua a non-semantic feature, in fixing the particular features of aesthetic judgment, for PPTs will turn out to have the same semantic profile as aesthetic predicates vis-à-vis experiencer-dependence. Thus, the 
difference between the judgments involved should be sourced to extra-linguistic factors, such as NAA.

One consideration often discussed, and raised above, is that PPTs appear to take judge arguments, prepositional phrases of the form, for/to me (cp., Stephenson, 2007; Glanzberg, 2007; Schaffer, 2011; Pearson, 2013). This feature is understood to distinguish PPTs from other non-personal predicates:

(11)a The ice cream is tasty to me

b ?The cake is frozen for/to me

It might be reasoned, therefore, that a PPT, unlike other predicates, in some sense selects or licenses the judge phrase. This reasoning is open to dispute (for extensive discussion, see Collins, 2013, but here I raise some novel issues).

Firstly, the phrase is an adjunct and so is not grammatically licensed or selected by any predicate at all. ${ }^{14}$ There are, it appears, obligatory adjuncts that attach to verbs such as word (He worded the letter well) and militate (The argument militated for the position), but PPTs transparently don't take obligatory adjuncts (cp., Grimshaw and Vikner 1993). Without further

\footnotetext{
${ }^{14}$ A precise characterisation of adjuncts (as opposed to arguments) is not required for my present point. Semantically speaking, an adjunct is often said to carry additional or modifying information on the thing, event, or state that is the value of the expression to which it attaches, such as spatio-temporal information. There is thus a certain rationale for viewing a judge phrase as non-adjunctional, as a judge or experiencer appears essential to the state a PPT picks out. Syntactically, however, the phrase is clearly an adjunct because it is optional. See author Collins, 2013, 2020.
} 
ado, there is no grammatical basis to think of the judge phrase as linguistically licensed; on the contrary, as an adjunct, it should enjoy no such licence.

Secondly, as argued above, although there is a clear difference between (11a) and (11b), it appears not to be a grammatical or linguistic difference. (11b) is merely an odd thing to say off the bat. In order to make it coherent, one would need to conjure up a scenario where people's standards of relative frozenness are somehow pertinent, not that a cake actually being frozen in terms of its temperature is somehow a matter of experience. The basic point, which generalises, is that judge phrases are acceptable with non-PPTs by way of imagining scenarios where speakers have variable standards that apply to the holding of any predicate. So much suggests that the difference between the cases in (11) is not linguistic but more broadly conceptual.

Thirdly, besides the considerations just raised, the judge phrase of (11a) does not unpack the content of the PPT anyway. The phrase provides a contrastive focus that expresses the presupposition that someone else does not find the ice cream tasty. With no such presupposition in play, (11a) has a questionable felicity. Compare the following dialogues:

(12) A: How's the ice cream?

B: ?It's tasty to me.

(13) A: How's the ice cream? C doesn't like it.

B: It's tasty to me.

B's personalised response in (12a) appears redundant and so odd in suggesting the relevance of the views of someone unmentioned; after all, only B was being addressed, and no-one else was at issue. In distinction, B's response in (13) is perfectly fine; indeed, at least equally felicitous as the bare It's tasty. This can only be because in the latter dialogue another person, 
$\mathrm{C}$, is at issue, whose experience of the ice cream may contrast with that of B's, rendering it appropriate for B to index her judgment of tastiness to herself.

This tells us that the judge phrase is not expressive of a covert content intrinsic to the PPT, but rather marks a contrast between the speaker and others. It remains true, of course, that if (11a) is to be true, then there must be someone for whom the ice cream is tasty. The present point is simply that the behaviour of the judge phrase does not indicate that this fact is semantically encoded as a feature of the PPT.

Fourthly, a speaker's denial of a positive attitude appended to a PPT assertion produces an off-the-bat anomaly akin to 'Moore's paradox':

(14)a \#The ice cream is tasty, but I don't like it

$\mathrm{b}$ \#The rollercoaster is fun, but I hate non-inertial movement

So much suggests that the initial clauses express a first-person perspective; hence the oddity of a concomitant denial in the second clause. This phenomenon does not militate for the syntactic or semantic projection of an experiencer argument, however; for the first-person perspective is only a default - either of the cases are fine, if the context of utterance makes it clear that the speaker is making the personal taste judgment on behalf of someone else, such as a child (see discussion of (5) above). To be sure, someone must find the ice cream tasty, if it is to be tasty at all, but we are presently looking for a reason to think that the experience-dependence of tastiness is a linguistically encoded property rather than an inference supported by our general metaphysical understanding of tastes.

A second consideration for PPTs to encode an experiencer/judge is more delicate and bears on PPTs that take infinitival complements, such as fun and exciting (tasty, for instance, takes no complements). When such complements lack any explicit subject or don't fall within the 
scope of a $w h$-item, the subject position, according to standard generative theories, is occupied by a covert item PRO, which can be controlled by some antecedent phrase, such as an argument of the matrix clause, or be arbitrarily construed akin to indefinite singular one. ${ }^{15}$ If, therefore, a structure has a control reading, there must be a controller, even if covert (cp., Glanzberg, 2007; Schaffer, 2011; Moltmann, 2010, 2012; Pearson, 2013). In this light, consider:

(15)a It is fun [PRO to dance]

b Rollercoasters are fun [PRO to ride on]

Whoever is dancing or riding on the rollercoasters is whoever is having fun doing so. It thus seems as if there is a covert experiencer controlling PRO:

(16)a It is fun $<$ for $x_{\mathrm{i}}>\left[\mathrm{PRO}_{\mathrm{i}}\right.$ to dance $]$

b Rollercoasters are fun $<$ for $x_{\mathrm{i}}>\left[\mathrm{PRO}_{\mathrm{i}}\right.$ to ride on]

The problem with this line of reasoning is that PRO is not obligatorily controlled in a complement infinitival clause:

(17)a It is common [PRO to dance]

b Rollercoasters are popular [PRO to ride on]

Here, it is events of dancing/riding on rollercoasters that are common and popular, respectively, but no-one who dances or rides is said to be common or popular. The mere presence of PRO in (17), therefore, does not mandate a covert controller. Of course, the choice of matrix predicate matters, and fun is different from the so-called 'quantificational predicates', such as popular or common; the present point is only that if one is in search of a reason for fun to project a covert experiencer argument, the presence of PRO in a complement clause is not

${ }^{15}$ See Landau (2013) for a review of theories of control. 
sufficient. All we can say so far is that if one assumes such an argument, then it does seem to act as a controller in (15). The readings of (15) remain to be explained, however, and it may seem that a covert argument is required to act as the controller. This line of thought is doubtful.

Note that the readings of (15) can be expressed without control:

(18)a To dance is fun

$\mathrm{b}$ To ride rollercoasters is fun

In these constructions, a putative covert experiencer cannot control the covert subject of the infinitival clauses. ${ }^{16}$ This tells us that PRO here is generically or arbitrarily interpreted regardless of the presence of fun, much like (17). So, in (18), fun is simply a predicate of dancing/rollercoaster riding, which involves whoever is participating as the agent-no control and no covert experiencer. If that is right, then the exact same reasoning applies to (15). The one remaining issue is why a disjoint reading is ruled out, i.e., one where, say, who finds it fun is not dancing, but maybe watching it. Yet this reading is unacceptable because fun is predicated of the event kind involving a dancer; and so there is no-one else but the dancer who could find it fun. Thus, a disjoint reading is ruled out, not because there are two positions in the structure that must be referentially identical, but because the PPT predicate applies to the

$\overline{16}$ One might think that the cases in (18), in contrast to those in (15), are in some sense noncanonical such that the former kind of case is to be treated in terms of the latter. This gets the situation back to front. If any structure is canonical, it is the (18) variety. For example, (15a) exhibits $i t$-extraposition, i.e., the clause is spelt-out rightward outside of its semantically interpretable position as the subject of being fun. In support of this, there is clearly no reconstruction effect with (15a), i.e., the clause is not ambiguously interpretable low and high, as if the infinitve has moved; being fun is simply ascribed to the generic event type of dancing. 
event including the value of PRO. One might be tempted, in response, to think that the speaker could value the positions in the structure, but speakers don't value PRO, and that is perfectly general. Consider:

(19) It is expensive to dance

It is the dancer for whom it is expensive, no-one else, such as a potential spectator, even though a speaker might add, but I'm so rich, it is as if nothing or, and that is why I don't dance. Just so, It is fun to dance, but I can't due to my bad leg. That is not a contradiction, but the first clause has an invariant meaning whether stand-alone or with the qualifying second clause. So, the identity of the speaker cannot saturate the infinitival argument position. ${ }^{17}$

In the absence of other considerations, therefore, PPTs do not project a role for an experiencer or judge. The role in judgment for an agent who finds things fun or tasty is made obligatory by way of the relevant general concepts, not the lexical items or the syntactic structure that hosts them.

${ }^{17}$ Similar reasoning applies to a post-copular infinitive with an infinitive subject:

(i) To love is to suffer

Whoever loves is one who suffers; (i) can't mean that for one to love involves the suffering of another, although that is a perfectly fine thought. There is a constraint, therefore, that the two PROs must be jointly construed. It becomes at least plausible that arbitrary PRO is always bound by a covert operator in order to secure the sole interpretation (Epstein, 1984; Lebeaux, 2009). Note, however, that in such cases we have independent reasons to posit the two arguments to be jointly construed, i.e., the usual reasons to posit PRO, and the post-copular infinitive is predicated of the subject. We don't infer either of the argument positions, as in (16), on the basis of a disjoint construal being unacceptable. 


\section{2: The structure of beauty}

Let's assume that the NAA reflects some central features of the concepts whose expression it covers (beauty, sublimity, elegance, etc.). It does not exhaust the relevant concepts, or mark differences between them, but captures the general feature of universality and the concomitant normativity that constitutes the fundamental notion of aesthetic evaluation within which

various concepts are involved. It remains an open question whether the norm is encoded as a semantic feature in the relevant predicates and so a feature that is an essential component of the semantic interpretation of the constructions featuring the expression. We just saw that PPT predicates do not express any experiencer or judge role as part of their semantico-syntactic identity; this holds quite independently of whatever further conceptual or philosophical account of PPTs is offered. Using PPTs as a paradigm, therefore, we should have no a priori expectation that NAA, or any other putative norm, is reflected in the structure of the relevant predicates. And so it proves.

Firstly, judgments of beauty are experiential, but beautiful and related adjectives do not encode any experiencer as an argument; indeed, they are not even happy with an experiencer adjunct, unless construed with contrastive presupposition. In this regard, in fact, they are the same as PPTs. (20) is grammatically acceptable, but odd as discourse-initial:

(20) The painting is beautiful to me

The prepositional phrase is not an argument, but an adjunct that marks a contrast between the speaker and a presupposed other who doesn't find the painting beautiful. As regards NAA, the adjunct simply marks the speaker as disagreeing with the presupposed other person or maybe as having no interest in discussing the matter. What the adjunct does not do, grammatically speaking, is make explicit an essential feature of the meaning of the adjective. With PPTs, an off-the-bat use of the adjunct, with no relevant other person indicated, is anomalous due to the 
default understanding that a speaker of a PPT is at least speaking for herself, in the absence of other presupposed agents. Likewise, (20) is anomalous in the absence of another agent who has an opposing view to the speaker.

As noted in $\S 4$, Liao et al. (2016) and McNally and Stajanovic (2017) are right to think that a for $x$ phrase does not reflect or otherwise unpack the core meaning of the aesthetic adjectives, but this is not a peculiar property of such adjectives. The phrase $i$ s perfectly OK with a contrastive focus, whether the predicate is aesthetic or not, but the phrase is not an argument anyway, and so its unhappiness in an off-the-bat or discourse-initial context does not suggest that aesthetic adjectives are non-experiential. The fact is that no adjective, including PPTs, takes experiencer or judge arguments via prepositional phrases.

It might be thought that the infelicity of an experiencer/judge adjunct with PPTs is due to its redundancy, which is a feature of it, rather than an experiencer/judge not being encoded in the predicate. In other words, the idea might be that the PPT predicates do express the relevant subjectivity dimension, and so making this explicit with an adjunct produces a pleonastic effect, unless some emphasis is required, which would explain the contrastive use of for me. In distinction, aesthetic predicates, qua universal normative claims, are not indexed to the subject, and so the occurrence of the adjunct is infelicitous.

I acknowledge (insist on!) the redundancy of a first-person singular judge phrase adjunct, but, contra the argument just advertised, this fact appears not to be semantically encoded. The alternative explanation faces two problems. Firstly, as regards PPTs, an adjunct is not necessarily redundant or productive of anomaly precisely because an adjunct need not be firstperson singular (for me/you/them/him/her). A redundancy explanation would be plausible, if acceptable PPT adjuncts were restricted to the first person singular, given that we could then be precise on what kind of index is putatively encoded in the predicate. Since a range of 
adjuncts are available, neither one nor all of them can be encoded, which means that any given adjunct adds information as to whom finds the thing or stuff to be tasty, fun, or whatever. One might want to say that some notion of a generic judge is encoded in the predicate, but that would not render an adjunct redundant; on the contrary, a choice of adjunct would specify what is left lexically open.

Secondly, aesthetic predicates $d o$ admit experiencer/judge adjuncts, but only in a contrastive use. If the predicates lexically or semantically did allow indexing to an experiencer/judge only on pain of redundancy, then one should wonder why the contrastive use is acceptable at all. If the obtaining of a property expressed by some predicate is taken to be non-dependent upon experience, then even a contrastive adjunct obliges an experiential/judge construal. For example, The result of the calculation is five for me (with contrastive for me) is acceptable, but not as a remark upon the value of the calculation in-itself, as if mathematics were subjective, but only as a remark upon how one's reasoning went or how things appear to one, in contrast to someone else.

Hence, on the view being commended, there is a nice symmetry between PPTs and aesthetic predicates: there is no lexical interdiction or licence issuing from the predicate concerning the acceptability of an adjunct introducing an experiencer/judge; the acceptability of such adjuncts is generally conditioned by contrastive focus across all cases. The hypothesis of an asymmetry based upon lexical meaning gives rise to problems, as observed, which the commended account avoids.

A final consideration that points in the same direction as the above remarks bears upon the construal of find. Aesthetic predicates, like PPTs, are happy in clausal complements of find (the verb is polysemous between a discovery and impression construals - the latter construal is here relevant): 
(21)a I find it (to be) beautiful

b I find it (to be) tasty

c ? find it (to be) $200 \mathrm{~m}$ tall

The pattern exhibited, however, does not reflect a selection feature of find, for there is nosuch thing as an experiential clause. Find simply has an experiential construal (when not a 'discovery'), which means that its complement must be the content of an experience. (21c) kind of cases, therefore, are not linguistically untoward, but merely odd, for one is left wondering how the complements can be experiential contents. With some imagination, though, their status is ameliorable when we place the construction in a scenario where an impression is what is at issue, even an impression that a building, say, is $200 \mathrm{~m}$ tall. Acceptability grades off where no impression could be made germane (I find arithmetic to be incomplete). ${ }^{18}$ The bottom line is that the properties of find tell us about find, not the structural properties of its complements.

If the above is correct, then the basic features of our concept of beauty that inform NAA are not realised as semantic or syntactic constraints upon how the relevant predicates can be employed. Instead, the features are carried by the concepts expressed by a speaker making an aesthetic judgment. In this regard, aesthetic predicates are just like PPTs at the level of language; the differences between the two classes reside at a discursive level, conditioned by a norm, in the aesthetic case, rather than a narrow linguistic level.

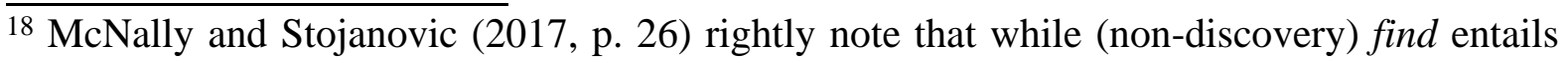
that the subject has had experience of the complement values, 'this entailment is not specifically diagnostic of properties whose very attribution is necessarily grounded in experience'. Acceptable grades off with greater difficulty in making sense of the entailment.
} 


\section{7: Conclusion}

The components of the position offered amount to something of a movable feast, although I think they are best consumed together. One might, for instance, accept NAA, but seek to ground it in the lexico-semantic properties of the relevant predicates. Such an endeavour faces problems, for the reasons broached in $\S 6$. One might look to reject NAA in favour of a less strict norm that reflects the messy ways in which people use aesthetic notions. Like Kant, however, my concern is to identify a precise kind of judgment and specify the appropriate norm governing it. Taking linguistic usage as our only guide will lead to no clear conception, I fear. So, NAA is idealised, but the truth is that many who employ aesthetic notions are simply expressing what is agreeable to them. It is not that they misuse the language; rather, they are simply not making an aesthetic judgment, and so not holding themselves to the relevant norm. As Kant admonished, it is hard to be sure when one's state of mind genuinely realises an aesthetic responsiveness properly deserving of the name. ${ }^{19}$

\section{References}

Brown, J. and Cappelen, H. (eds.) 2011: Assertion: New Philosophical Essays. Oxford: Oxford University Press.

Collins, J. 2013: The syntax of personal taste. Philosophical Perspectives, 27: 51-103. Collins, J. 2020: Linguistic Pragmatism and Weather Reporting. Oxford: Oxford University Press.

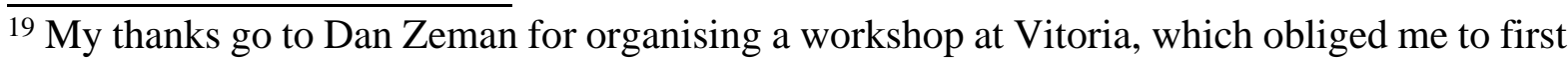
think of these issues. Hazel Pearson suggested a crucial amendment to my position, and I am grateful to others for enlightenment, especially Lisa Bylinina, Carla Umbach, Agustin Vicente, and Katie Fraser.
} 
Egan, A. 2010: Disputing about tastes. In R. Feldman and T. Warfield (eds.), Disagreement (pp. 247-286). Oxford: Oxford University Press.

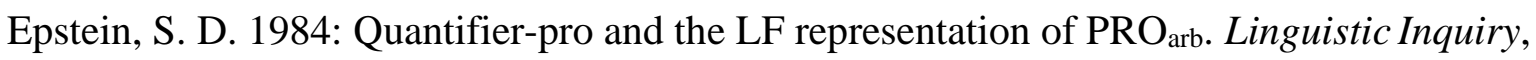
15: 499-504.

Frankfurt, H. 1986: On bullshit. Raritan Quarterly Review, 2: 81-100.

Glanzberg, M. 2007: Context, content, and relativism. Philosophical Studies, 136: 1-29.

Gorodeisky, K. 2010: A new look at Kant's account of testimony. The British Journal of Aesthetics, 50: 53-70.

Grimshaw, J. and Vikner, S. 1993: Obligatory adjuncts and the structure of events. In E. Reuland and W. Abraham (eds.), Knowledge and Language II: Lexical and Conceptual Structure (pp. 143-155). Dordrecht: Kluwer.

Hopkins, R. 2000: Beauty and testimony. In A. O'Hear (ed.), Philosophy, the Good, the True and the Beautiful (pp. 209-236). Cambridge: Cambridge University Press.

Hopkins, R, 2011: How to be a pessimist about aesthetic testimony. Journal of Philosophy, 108: $138-157$.

Kant, I. 1790/2000: Critique of the Power of Judgement. Cambridge: Cambridge University Press.

Kölbel, M. 2004: Faultless disagreement. Proceedings of the Aristotelian Society, 104: 53-73.

Kölbel, M. 2008: Introduction: motivations for relativism. In M. Garcia-Carpintero and M.

Kölbel (eds.), Relative Truth (pp. ). Oxford: Oxford University Press.

Kölblel, M. 2016: Aesthetic judge-dependence and expertise. Inquiry, 59: 589-617.

Landau, I. 2013: Control in Generative Grammar: A Research Companion. Cambridge:

Cambridge University Press.

Lasersohn, P. 2005: Context dependence, disagreement, and predicates of personal taste. Linguistics and Philosophy, 28: 643-686.

Lasersohn, P. 2017: Subjectivity and Perspective in Truth-Theoretic Semantics. Oxford: 
Oxford University Press.

Lebeaux, D. 2009: Where does Binding Theory Apply? Cambridge, MA: MIT Press.

Liao, S., McNally, L., and Meskin, A. 2016: Aesthetic adjectives lack uniform behaviour. Inquiry, 59: 618-631.

López de Sa, D. 2015: Expressing disagreement: A presuppositional indexical contextualist relativist account. Erkenntnis, 80: 153-165.

MacFarlane, J. 2005: Making sense of relative truth. Proceedings of the Aristotelian Society, 105: $305-323$

MacFarlane, J. 2007: Relativism and disagreement. Philosophical Studies, 132: 17-32.

MacFarlane, J. 2014: Assessment Sensitivity: Relative Truth and its Applications. Oxford:

Oxford University Press.

Meskin, A. 2004: Aesthetic testimony: what can we learn from others about beauty and art? Philosophy and Phenomenological Research, 69: 65-91.

Moltmann, F. 2010: Relative truth and the first person. Philosophical Studies, 150: 187-220

Moltmann, F. 2012: Two kinds of first-person-orientated content. Synthese, 184: 157-177.

Ninan, D. 2014: Taste predicates and the acquaintance inference. Proceedings of SALT, 24: 290-309.

Pearson, H. 2013: Judge-free semantics for predicates of personal taste. Journal of Semantics, 30: 103-154.

Plunkett, D., and Sundell, T. 2013: Disagreement and the semantics of normative and evaluative terms. Philosophers' Imprint, 13: 1-37.

Richard, M. 2008: When Truth Gives Out. Oxford: Oxford University Press.

Robson, J. 2012: Aesthetic testimony. Philosophy Compass, 7: 1-10. 
Robson, J. 2015: Aesthetic testimony and the norms of belief formation. European Journal of Philosophy, 23: 750-763.

Robson, J. 2018: Aesthetic testimony and the test of time. Philosophy and

Phenomenological Research, 96: 729-748.

Schaffer, J. 2011: Perspective in taste predicates and epistemic modals. In A. Egan and B.

Weatherson (eds.), Epistemic Modality (pp. 179-226). Oxford: Oxford University Press.

Sibley, F. 1959: Aesthetic concepts. Philosophical Review, 68: 421-450.

Silk, A. 2016: Discourse Contextualism: A Framework for Contextualist Semantics and Pragmatics. Oxford: Oxford University Press.

Stephenson, T. 2007: Judge dependence, epistemic modals, and predicates of personal taste. Linguistics and Philosophy, 30: 487-525.

Stojanovic, I. and McNally, L. 2017: Aesthetic adjectives. In J. O. Young (ed.), Semantics of Aesthetic Judgements (pp. 17-37). Oxford: Oxford University Press.

Sundell, T. 2016: The tasty, the bold, and the beautiful. Inquiry, 59: 793-818.

Sundell, T. 2017: Aesthetic negotiation. In J. O. Young (ed.), Semantics of Aesthetic Judgements (pp. 82-105). Oxford: Oxford University Press.

Williamson, T. 2000: Knowledge and Its Limits. Oxford: Oxford University Press. Wright, C. 1992: Truth and Objectivity. Cambridge, MA: Harvard University Press. Young, J. O. (ed.) 2017: Semantics of Aesthetic Judgements. Oxford: Oxford University Press. 